\title{
Bullying: verificando a compreensão dos professores sobre o fenômeno no ambiente escolar
}

\author{
Maria Teresa Ceron Trevisol \\ Universidade do Oeste de Santa Catarina - Joaçaba - SC - Brasil \\ Carlos Alexandre Campos \\ Universidade do Oeste de Santa Catarina - Joaçaba - SC - Brasil
}

\begin{abstract}
Resumo
Este artigo objetiva analisar a compreensão que professores que atuam na $8^{\text {a }}$ série $/ 9^{\circ}$ ano do ensino fundamental, de um município localizado na região oeste de Santa Catarina possuem acerca das razões promotoras do bullying no ambiente escolar; a natureza destas razões; como avaliam as manifestações deste problema e quais as estratégias utilizadas pela escola para encaminhar situações de conflito entre os alunos. A base empírica deste artigo é uma pesquisa de cunho exploratório e de natureza qualitativa. Identificaram-se, por parte dos professores pesquisados, alguns conhecimentos em relação ao bullying. Faz-se necessário repensar as matrizes curriculares dos cursos de formação dos futuros professores, articulando conhecimentos científicos e questões práticas que emergem do cotidiano escolar. A compreensão do problema bullying pelos professores terá repercussões na maneira como planejam e realizam suas intervenções no contexto da escola.
\end{abstract}

Palavras-chave: Bullying; escola; professores de ensino fundamental.

\section{Bullying: checking the understanding of teachers about the phenomenon in the school environment}

\begin{abstract}
This article aims to analyze the teachers understanding about the promoters reasons of bullying in the school environment, how they understand the nature of these reasons, to evaluate the manifestations of this problem and the strategies used by the school to direct conflicts among the students. The interviewed teachers work in grade $8 / 9$ th grade of elementary school, a municipality located in the western region of Santa Catarina. The empirical basis of this article is an exploratory and qualitative research. They were identified by the surveyed teachers, some knowledge regarding the bullying. It is necessary to rethink the curriculum matrices of training courses for future teachers, linking scientific knowledge and practical issues that emerge from school everyday. Understanding the problem bullying by teachers will affect the way they plan and carry out their activities in the school context.
\end{abstract}

Keywords: Bullying; school; elementary school teachers.

\section{Bullying: comprobando la comprensión de los profesores sobre el fenómeno en el ambiente escolar}

\section{Resumen}

Este artículo tiene como objetivo analizar la percepción de los maestros que trabajan en el grado 8/9 de la escuela primaria de un municipio situado en la región oeste de Santa Catarina tienen acerca de las razones promotoras del bullying en el ambiente escolar; la naturaleza de estas razones; como evalúan las manifestaciones de este problema y las estrategias utilizadas por la escuela para dirigir los conflictos entre los estudiantes. La base empírica de este artículo es una investigación de carácter exploratorio y cualitativo. Fue identificado, por los profesores investigadores, un poco de conocimiento con relación al bullying. Es necesario repensar las matrices curriculares de los cursos de formación de futuros docentes, vinculando el conocimiento científico y las cuestiones prácticas que emergen de la escuela todos los días. La comprensión del problema del bullying por los profesores afectará la forma como planean y realizan sus intervenciones en el contexto escolar.

Palabras clave: La intimidación; la escuela; maestros de escuelas primarias. 


\section{Introdução}

O ambiente escolar se caracteriza como um local privilegiado para se refletir sobre as relações sociais que envolvem crianças e jovens, pais e filhos, educadores e educandos. É também no contexto escolar que fatores como a socialização, a promoção da cidadania e o desenvolvimento pessoal podem modificar-se tanto positiva quanto negativamente (Marriel, Assis, Avanci, \& Oliveira, 2006).

Dentre as temáticas relativas à instituição escolar, a ocorrência, as manifestações e encaminhamentos em relação ao bullying, neste ambiente, têm sido tema reiteradamente investigado tanto no Brasil quanto em outros países. A palavra bullying possui origem inglesa, bully, que significa valentão e é utilizada para dar nome "ao desejo consciente e deliberado de maltratar outra pessoa e colocá-la sob tensão" (Fante \& Pedra, 2008, p. 41). Segundo Avilés Martínez (2006, p.82) o bullying se refere "à intimidação e o maltrato entre escolares de forma repetida e mantida no tempo, sempre longe dos olhares dos adultos/as, com a intenção de humilhar e submeter abusivamente uma vítima indefesa [...]".

Vários sinônimos têm sido utilizados em português para fazer referência ao tema, dentre eles: "maus tratos, vitimização, intimidação, agressividade e violência entre pares" (Almeida, Lisboa, \& Caurcel, 2007; Lopes Neto, 2005; Pereira, 2002; Silva, Oliveira, Silva, Pereira, \& Cecilio, 2015; Tognetta, Leme, \& Vicentin 2013). O bullying “... acarreta sofrimento psíquico, diminuição da autoestima, isolamento, prejuízos no aprendizado e no desempenho acadêmico" (Moura, Cruz, \& Quevedo, 2011).

As vítimas desse fenômeno podem sofrer danos psíquicos difíceis de reparar e, eventualmente, podem desenvolver quadros depressivos; apresentam dificuldades em relacionar-se com outras pessoas, passam a ter dificuldades no aprendizado, podendo inclusive assumir a posição de agressores em novas situações de bullying (Lopes Neto, 2005). Alvos, autores e testemunhas enfrentam consequências físicas e emocionais a curto e longo prazo (Silva \& Rosa, 2013).

Embora seja um tema antigo, os estudos científicos sobre tal temática só iniciaram-se na década de 1970, mais precisamente na Suécia (Silva, 2010). Alguns anos mais tarde, o pesquisador norueguês Dan Olweus iniciou os estudos científicos sobre o bullying no âmbito escolar em seu país, realizando uma pesquisa que reuniu, aproximadamente, oitenta e quatro mil alunos, quase 400 professores e cerca de mil pais de alunos, objetivando avaliar as taxas de ocorrência e as formas pelas quais o fenômeno bullying se apresentava na vivência escolar dos alunos pesquisados (Silva, 2010).

Atrelando-se a este contexto, a Associação Brasileira Multiprofissional de Proteção à Infância e à Adolescência (2008) afirma que o bullying pode ser caracterizado como um problema mundial e que, embora possa ser encontrado em qualquer instituição escolar, algumas escolas ainda não admitem a ocorrência deste fenômeno entre seus educandos, quer seja porque não têm conhecimento do problema, ou porque preferem negar a ocorrência deste.
$\mathrm{Na}$ interface bullying e ambiente escolar há um mediador que não pode ser esquecido: o professor. Este profissional, entretanto, nem sempre foi (cursos de formação inicial de professores ou de formação continuada) ou está preparado para identificar e encaminhar as situações de bullying na escola. Estudo realizado por Silva e Rosa (2013) investigou as demandas formativas de professores já formados ou em processo de formação inicial para lidar com jovens do $6^{\circ}$ ao $9^{\circ}$ ano do ensino fundamental em termos de conhecimentos e maneiras de intervir nas situações de bullying na escola. Os dados coletados revelaram que a respeito do conceito de bullying os entrevistados deram respostas que variavam de posicionamentos superficiais e pouco delimitados até definições mais precisas e próximas do que afirmam os estudiosos da área; definiam o bullying como agressões verbais ou físicas, perseguição e apelidos, ou simplesmente não emitiam opinião sobre o tema. Nesse sentido, a falta de conhecimentos a respeito do problema "... tem repercussões nos modos dos professores planejarem e realizarem suas intervenções pedagógicas neste campo" (Silva \& Rosa 2013, p. 336) e "favorece posturas imobilistas diante das ocorrências da escola" (Silva \& Rosa, 2013, p. 334).

Em outro estudo realizado por Gisi, Vaz e Valter (2012, p. 4) confirma-se que o bullying não é uma temática suficientemente trabalhada no processo de formação profissional, e que "a escola hoje se apresenta com um perfil bastante diferente e para tanto os professores requerem uma formação mais abrangente e uma reformulação nos currículos existentes nos cursos de licenciatura".

Baseando-se nos princípios supracitados, bem como na literatura científica nacional e internacional sobre a temática, o foco deste artigo é analisar a compreensão de professores que atuam na $8^{\mathrm{a}}$ série $/ 9^{\circ}$ ano do ensino fundamental acerca das razões promotoras do bullying no ambiente escolar; a natureza das razões que podem promover as manifestações deste fenômeno; como estes avaliam as manifestações de bullying na escola e quais as estratégias utilizadas pela escola para resolver conflitos do cotidiano escolar.

\section{Método}

A base empírica deste artigo é uma investigação de cunho exploratório e de natureza qualitativa. A pesquisa foi realizada em quatro escolas de um município do meio oeste catarinense, sendo duas escolas da rede pública (uma municipal e uma estadual) e duas escolas da rede privada. Não constituiu objetivo da investigação realizada efetuar uma análise comparativa entre os dados destas instituições. A amostra foi composta por 18 professores que atuam na $8^{a}$ série $/ 9^{\circ}$ ano do Ensino Fundamental dentre os 39 que compõem o total de sujeitos que atuam nesse ano letivo. Cabe ressaltar que a amostra composta por professores constitui o prosseguimento de uma investigação, iniciada em 2012, tendo como amostra alunos matriculados na $8^{\mathrm{a}}$ série $/ 9^{\circ}$ ano 
do ensino fundamental ${ }^{1}$ de um município da região oeste catarinense. No ano de 2014, deu-se continuidade à investigação tendo como foco professores e pais de alunos que frequentam o $8^{\circ}$ ou $9^{\circ}$ ano do ensino fundamental. Dessa forma, o conjunto dos dados coletados permitiu uma compreensão mais apurada em relação a uma faceta de sujeitos envolvidos com o contexto escolar e intérpretes de situações de bullying vivenciadas nesse contexto.

Dos professores pesquisados, 16 são do sexo feminino e dois do sexo masculino, na faixa de idade entre 25 e 55 anos. Quanto ao tempo de docência destes, o mínimo é de seis meses e o máximo de 35 anos. A maioria dos professores pesquisados, que perfaz um total de seis, ministravam a disciplina de Língua Portuguesa. Acerca do grau de escolaridade dos mesmos, 13 professores apresentavam pós-graduação (especialização) completa. A escolaridade mínima verificada foi de dois professores que apresentavam a graduação completa, e a escolaridade máxima verificada foi de um professor que apresentava pós-graduação (mestrado) completa.

Como procedimento de coleta de dados foi utilizado um questionário composto por 19 questões, abertas e fechadas e que solicitavam as seguintes informações: compreensão dos professores sobre o bullying; casos e ocorrências de bullying na escola; atitudes e estratégias de encaminhamento do problema. Os sujeitos pesquisados foram consultados em relação a seu interesse em participar da investigação e os que se posicionaram favoráveis à participação na pesquisa receberam um Termo de Consentimento Livre e Esclarecido e o assinaram². Os questionários foram entregues aos professores e foi combinada a devolutiva com eles. Os pesquisadores voltaram às escolas para apanhar os questionários preenchidos.

As respostas às questões fechadas foram digitadas e tabuladas com a utilização de uma ferramenta online (Google Docs). As respostas das questões abertas foram analisadas por meio da análise do conteúdo.

\section{Resultados e Discussão}

Os resultados obtidos por meio deste estudo serão apresentados juntamente com a respectiva discussão.

\footnotetext{
1 Nos anos de 2012 e 2013 desenvolveu-se um projeto de pesquisa intitulado Bullying na escola: inquirindo sobre as razões promotoras dos conflitos "entre" e "dos" alunos (Trevisol \& Uberti, 2013), buscando analisar a compreensão de alunos adolescentes que frequentam a $8^{a}$ série/ $9^{\circ}$ ano do ensino fundamental quanto às razões promotoras de manifestações de bullying em sua escola; como se posicionam frente a estas manifestações; e como avaliam os encaminhamentos tomados pela escola e por seus profissionais visando solucionar as situações envolvendo conflitos entre e dos alunos.

20 projeto de pesquisa foi aprovado pelo Comitê de Ética em Pesquisa (CEP/UNOESC), de acordo com o parecer consubstanciado número 491.199.
}

\section{Compreensão dos professores sobre o bullying}

No que se refere ao conhecimento da temática do bullying, os 18 professores pesquisados afirmaram já ter ouvido falar sobre este fenômeno. Embora seja raro encontrar algum professor que não tenha algum conhecimento - mesmo que básico - acerca do bullying, a problemática principal reside em como os docentes agem frente a tais situações.

Quanto à compreensão acerca do bullying, 11 entre os 18 professores compreendem o fenômeno como sendo um tipo de violência ou agressão individual (física, verbal, atitudinal, entre outras); cinco o compreendem como sendo atitudes de desrespeito que causam constrangimento e abalam a autoestima, dois caracterizam-no como um comportamento agressivo, dois compreendem-no como algo que humilha o outro, dois entendem como a crítica que alguém sofre por ser "diferente" sob alguns aspectos que o diferencie ou destaque da maioria, e um sujeito compreende o bullying como brincadeiras de mau gosto repetitivas. Lopes Neto e Saavedra (2003, p. 18) afirmam que o bullying "... compreende todas as atitudes agressivas, intencionais e repetitivas que ocorrem sem motivação evidente, adotadas por um ou mais estudantes contra outro(s), causando dor e angústia, e executadas dentro de uma relação desigual de poder...". Ainda neste contexto, tendo em vista a compreensão de um professor acerca de que o bullying pode ser caracterizado como sendo brincadeiras de mau gosto repetitivas, Fante (2005) enfatiza que o bullying não se caracteriza como brincadeiras próprias de criança, mas constitui-se como um fenômeno gerador de sofrimento.

Atrelando-se ao exposto, no que concerne à visão dos professores acerca do problema do bullying, cinco dos sujeitos pesquisados avaliam o bullying como um problema muito sério, três que o bullying configura-se como um desajuste e/ou desequilíbrio comportamental do indivíduo, dois configuram-no como um problema social, dois que o bullying sempre existiu, enquanto um acredita que este seja uma consequência da modernidade. Um professor, ainda, acredita que o bullying é fruto da distorção de valores e um docente crê que o bullying configura-se como um desafio para as equipes educacionais. Pode-se analisar que a compreensão dos professores acerca do bullying é, em sua maioria, convergente, pois estes avaliam o problema como sério e consideram que o seu encaminhamento constitui um desafio para a escola. Silva e Rosa (2013, p. 330) enfatizam que "é importante frisar que antes de classificar um ato de violência como bullying deve-se analisar o contexto situacional, levando-se em consideração as características individuais das pessoas envolvidas, bem como os contextos familiar e escolar, pois estes núcleos sociais influenciam o comportamento do indivíduo". O bullying não deve ser avaliado de modo descontextualizado desse conjunto de variáveis: pessoal, familiar, escolar e social.

Acerca de como tiveram contato com a temática do bullying, 16 professores afirmaram ser por meio da mídia, 11 por meio da Internet, oito disseram ser por meio da participação em cursos, três afirmaram ser por meio de livros 
científicos e dois por outros meios, tais como palestras e campanhas que ocorreram nas escolas. Quando questionados acerca de terem recebido, em sua atuação profissional, capacitação sobre violência nas escolas, 11 professores responderam afirmativamente e sete responderam negativamente. Verifica-se que embora os professores afirmem ter conhecimento acerca da temática, por diversos motivos não buscam compreendê-la sob a perspectiva científica, fato respaldado quando da análise do número de docentes que afirmaram ter tido contato com o tema por meio de livros científicos.

Quanto às agressões que ocorrem em situações de bullying, 17 participantes responderam que consideram as agressões verbais (tais como gritar, xingar e ofender) e relacionais (como, por exemplo, humilhar, excluir do grupo, falar mal) como sendo inerentes à situação; 15 professores consideram as agressões físicas (tais como chutar, bater e empurrar) como também sendo inerentes à situação da ocorrência de bullying. Dois docentes sinalizaram que há, em suas opiniões, outro tipo de agressão que também caracteriza a ocorrência do bullying, sendo este o cyberbullying, acerca do qual Tognetta e Bozza (2010) inferem que “... com a chegada e o crescimento acelerado da tecnologia, surgiu uma nova forma de intimidação, que ultrapassou o aspecto físico presencial - o Cyberbullying - uma forma dissimulada de Bullying, em que as agressões são virtuais". Segundo Avilés Martínez (2013, p. 11) “... meninos e meninas agem mal e menosprezam o outro virtualmente porque heteronomamente, na ausência de uma autoridade que possa vigiar ou castigar, se acham livres para fazê-lo".

\section{Causas, responsabilidade da escola e papel da família no bullying}

No que se refere às possíveis causas do bullying, 13 professores acreditam que a convivência familiar do educando é o fator primordial para a ocorrência de tais situações, cinco acreditam que o preconceito e a crítica ao diferente é o que leva à ocorrência do fenômeno, cinco docentes inferem que a falta de diálogo é a causa do problema, quatro afirmam que o uso e abuso de drogas e outros vícios levam à ocorrência do bullying, três professores acreditam que a má influência dos meios de comunicação é o fator que incita à ocorrência do fenômeno. Dois professores acreditam que o fato do aluno ter sido alvo de violência (tanto familiar quanto entre os colegas) pode ser a causa que os leve a praticar bullying, dois consideram que a fragilidade emocional é a causa do bullying, dois professores acreditam que a intolerância e o individualismo propiciam a ocorrência do bullying no ambiente escolar, um professor crê que a má influência dos colegas pode ser considerada a causa do fenômeno e um outro acredita que a má comunicação entre a família e a escola pode ser tida como a causa do bullying. Considerando quais seriam as causas do comportamento relativo ao bullying, Fante e Pedra (2008) inferem que diversos estudos foram desenvolvidos na tentativa de compreender tal fenô- meno tendo em vista os diversos aspectos a ele relacionados, a saber: familiar, social, cultural, afetivo e emocional.

Além dos aspectos supracitados, Fante e Pedra (2008) discorrem acerca da existência da alta competitividade na escola e na família, que consiste em um fator gerador do individualismo, bem como a dificuldade de empatia, a crise ou ausência de modelos educativos baseados em valores humanos que podem caracterizar-se como as possíveis causas para a ocorrência do bullying. Em consonância com essa compreensão Pereira, Silva, e Nunes (2009) ressaltam a importância de se analisar o clima que se cria na escola, pouco favorável à cooperação e, da mesma forma, o próprio clima familiar embasado na competição. Sobre tal aspecto os autores (Pereira, Silva, \& Nunes, 2009) se manifestam:

a educação da criança na família está muito centrada na competitividade e na vitória a qualquer preço e não está a ser direcionada para a aquisição de competências graduais, de acordo com a idade e adquiridas pela cooperação e solidariedade. E a escola, em vez de corrigir este enviesamento vai reforçá-lo de inúmeras formas contribuindo para o clima de indiferença que se está a observar (p. 465).

Quanto ao que os professores pensam acerca da escola ter responsabilidade em relação ao problema do bullying, 12 professores responderam afirmativamente, três responderam que a responsabilidade deve ser da escola, da família e da sociedade, um docente afirmou que a escola não é responsável diretamente, um relatou que a escola não é a principal responsável e, ainda, um participante respondeu que a escola "Tem a responsabilidade de cultivar a boa convivência entre os alunos. Mas a escola não é culpada pelo caso de bullying que venha a acontecer... O aluno é responsável pelas próprias atitudes, e consequentemente os pais, pela educação que dão aos filhos (P1)". Segundo Rosa (2010, p. 154), “... a prevenção deve começar em casa, com a devida educação e repasse de valores éticos e morais aos filhos, mas quando isso não é suficiente... cabe à escola promover essa reflexão", ou seja, pode-se analisar que a responsabilidade não deve ser totalmente delegada nem à família, nem à escola, mas sim que ambas devem buscar meios de orientar as crianças e os adolescentes perante tal problemática, constituindo-se o diálogo numa ferramenta de extrema importância tanto para o esclarecimento de dúvidas em relação ao fenômeno bullying quanto para a relação de confiança que deve haver entre aluno, professor, filhos e pais, para que o educando sinta-se seguro e encorajado a agir do modo mais habilidoso possível perante tais situações.

Sobre a importância da família, os professores acreditam que o diálogo familiar consiste na melhor forma para o combate e resolução dos problemas de bullying, além de acreditarem que a família também deve aprender sobre o bullying e os sinais que a criança emite quando está em sofrimento. Também pensam que a família deve acompanhar, conhecer e fazer parte da vida dos filhos e garantir um ambiente saudável a estes. Esses argumentos são corroborados pelo 
estudo realizado por Borsa, Petrucci e Koller (2015, p. 42) que define o bullying "como um fenômeno multideterminado", destacando a necessidade de incluir os pais como participantes nos estudos empíricos considerando suas contribuições para a avaliação e prevenção do problema. Além disso, os pais "podem fornecer informações importantes sobre a família e sobre os comportamentos da criança fora do ambiente escolar e assim contribuir para uma melhor compreensão dos fatores motivadores e mantenedores dos comportamentos agressivos e da vitimização da criança em situações de bullying" (Sawyer, Mishna, Pepeler, \& Wiener, 2011 conforme citado por Borsa, Petrucci, \& Koller, 2015, p. 43).

Considerando o posicionamento dos professores acerca da fundamental importância do diálogo familiar, de conhecer o mundo dos filhos e deixá-los conhecer o seu e do ambiente acolhedor que a família deve proporcionar, Avilés Martínez (2013, p. 12) sugere uma modalidade de intervenção designada como "os fóruns com as famílias". Mais do que cobrar por medidas e exigências políticas, mais do que denunciar o problema das famílias malformadas, mal instruídas sobre a educação de seus filhos, é preciso abrir espaços para se pensar, conjuntamente, o problema da qualidade das relações com aqueles que mais podem auxiliar nesse desenvolvimento: os educadores e os pais.

\section{Ocorrência de situações de bullying na escola}

No que tange à ocorrência do bullying na escola em que os professores pesquisados atuam, nove afirmaram que houve ocorrência do problema, enquanto oito disseram que não houve situações de bullying na escola. Neste contexto, Fante e Pedra (2008, p. 50) afirmam que "infelizmente, o fenômeno vem crescendo em todo o mundo". Pelos dados obtidos, percebe-se que alguns professores e algumas escolas tendem a negar e/ou não visualizar as ocorrências do fenômeno bullying, relatando, portanto, que não houve situações de bullying na escola em que trabalham, afirmação que pode ser bastante questionada, uma vez que se sabe que a ocorrência desta prática de violência, apesar de silenciosa, está presente em todas as instituições educativas, variando apenas os índices encontrados em cada realidade escolar (Fante \& Pedra, 2008).

Sobre terem presenciado a ocorrência de alguma situação de bullying no ambiente escolar, sete professores assinalaram que já presenciaram e 11 assinalaram não terem presenciado situações de bullying na escola. A ocorrência do bullying não está restrita a algum tipo específico de escola, o fenômeno está presente em escolas de todo o mundo, independente de serem públicas ou privadas, primárias ou secundárias e estarem localizadas na zona urbana ou rural. Acerca do procedimento que deve ser adotado pelos professores ao presenciar a vitimização, Fante e Pedra (2008, p. 116) afirmam que "o professor deve intervir imediatamente, de forma que cessem os ataques... No entanto, o professor deve ter muito cuidado para não expor o autor a situações de constrangimento [...] nem superproteger a vítima, impedindo que desenvolva a capacidade de autodefesa", complementando ainda sobre a importância de o professor agir com discrição ao orientar o aluno, respeitando sempre a personalidade do mesmo, as limitações e as condições inerentes à cada faixa etária e sem deixar de considerar que deve merecer especial atenção por parte dos profissionais que atuam na escola o trabalho a ser desenvolvido com "as testemunhas ou espectadores". A testemunha ocupa papel importante nas ocorrências do bullying; "não há bullying sem que haja um público a corresponder com as apelações de quem ironiza, age com sarcasmo e parece liderar aqueles que são espectadores" (Tognetta \& Vinha, 2010, p. 452). Então, quando a testemunha se indigna e se manifesta em relação ao autor do bullying, quando defende o alvo ou quando pede ajuda a um adulto rompe com as expectativas de aceitação e motivação social por parte do autor (Trevisol \& Uberti, 2015).

Quando questionados sobre o fato de algum (a) aluno (a) já ter-lhe procurado para relatar alguma situação de bullying, quatro professores afirmaram que sim e onze que não. Este fato reforça as afirmações de que muitos alunos se mantêm em silêncio quando são vítimas de bullying e, por diversas vezes, não relatam aos seus professores sobre a situação vivenciada. Nesse sentido, cabe considerar dados de uma pesquisa realizada por Trevisol e Uberti (2015), com 171 alunos da $8^{a}$ série $/ 9^{\circ}$ ano do ensino fundamental, procedentes de escolas públicas e particulares localizadas na região oeste catarinense, em que Ihes foi questionado para quem comunicam episódios de bullying. Entre os alunos que explicitaram ter passado por situações de bullying, 26,56\% dos de escola particular e $18,69 \%$ da escola pública contaram aos pais; $15,63 \%$ dos estudantes de escola particular e $16,82 \%$ da escola pública contaram para colegas/amigos; $20,31 \%$ dos alunos de escola particular não disseram para ninguém e a mesma atitude foi tomada por $9,35 \%$ dos alunos da escola pública. Cabe destacar que um número pequeno contou a situação para professores (escola particular: 4,69\% e escola pública: $3,74 \%$ ) e direção (escola particular: $6,25 \%$ e escola pública: $5,61 \%$ ). Tal dado merece atenção considerando que as figuras de proteção: diretores, professores ou outros profissionais que atuam na escola, nem sempre estão sendo autorizadas pelos alunos a tomar conhecimento do que está acontecendo com eles ou em parceria com eles tomarem providências em relação aos problemas vivenciados. Estaria na essência dessa constatação a ausência de sentimentos de confiança dirigidos a esses profissionais?

\section{Discussão da temática, projetos de intervenção, estratégias e apoio de outros profissionais para combater o bullying}

Quando questionados acerca de terem conversado sobre o bullying com seus alunos, os dezoito professores pesquisados responderam afirmativamente. Sabe-se que o fato de os professores conversarem com os seus alunos sobre o bullying pode ser um fator que auxilie na redução 
dos casos, bem como esclareça as particularidades deste fenômeno; entretanto, se torna imprescindível que os professores tenham conhecimentos concretos acerca desta temática, a fim de que possam dialogar com propriedade e esclarecer as dúvidas que surgirem.

Quando questionados acerca da existência de projetos de intervenção e/ou prevenção focados no bullying na escola em que atuam, oito professores responderam positivamente, nove responderam negativamente e um (01) respondeu não saber acerca da existência ou não de tais projetos na escola em que atua. Deve-se reconhecer que a existência de projetos de intervenção e/ou prevenção focados no bullying são de extrema importância, pois podem proporcionar o esclarecimento de dúvidas acerca da temática, bem como incentivar as vítimas a relatarem o sofrimento vivenciado e, sobretudo, reduzir os casos de ocorrência do fenômeno.

No que tange às atitudes e/ou estratégias que a escola deve adotar para combater o bullying, seis docentes afirmam que atividades de conscientização e sensibilização devem ser adotadas; quatro afirmam que deve haver uma discussão aberta sobre os incidentes de bullying; quatro professores compreendem que a tolerância e o respeito no convívio devem ser incentivados; três declaram que deve haver projetos específicos para trabalhar acerca de tal temática; três participantes acreditam que o trabalho em grupo, as peças teatrais, as atividades esportivas e as campanhas podem ser fontes satisfatórias para o combate ao bullying; dois professores afirmam que reflexões acerca do bullying consistem em uma boa estratégia para combatê-lo; dois acreditam que se deve trabalhar a questão comportamental, incitando à mudança de comportamento dos alunos para que a ocorrência de casos de bullying minimize-se; dois professores creem que, quando da ocorrência de situações de bullying, as providências devem ser tomadas de modo ágil e concreto, para que seja possível, assim, combater tal situação; um professor acredita que impor limites é uma estratégia para combater o bullying; um docente pensa que monitorar as atitudes dos alunos dentro da escola pode ser uma estratégia satisfatória para combater o bullying; um infere que envolver os alunos que sofrem e/ou sofreram bullying em atividades com os demais pode ser algo eficaz para minimizar a ocorrência do fenômeno; um professor acredita que agir com rigidez pode combater esta prática no contexto escolar e um outro pensa que qualificar professores, pais e coordenadores para detectar casos de bullying consiste em uma estratégia eficaz para o combate destes casos. Cabe destacar no conjunto dessas respostas que a maioria das atitudes e/ou estratégias elencadas se referem à realização de atividades direcionadas aos alunos e somente uma delas elas enfatiza a necessidade de capacitação dos profissionais que atuam na escola. Merecem atenção alternativas de encaminhamento do problema que possam ser organizadas no e pelo contexto escolar e que primem por projetos que visem a convivência entre os envolvidos neste contexto: alunos, professores, direção, funcionários, pais, entre outros.
No que se refere a receber ou não apoio de outros profissionais da escola para lidar com situações que se refiram ao bullying, os professores pesquisados afirmaram contar com o auxílio de outros profissionais para esses casos. Os profissionais por eles citados foram os seguintes: diretores, coordenadores pedagógicos, apoio pedagógico, orientadores educacionais, psicólogos e gestores. Um docente citou que, além da equipe da escola, conta também com o auxílio da polícia. Acerca dos profissionais citados, Esteve e Arruda (2014, s. p.) afirmam que "O bullying no Brasil ainda é algo muito novo e por isso professores, diretores, coordenadores, muitas vezes não o conhecem profundamente e não sabem como lidar com esse problema", o que corrobora com as afirmações inseridas acerca da falta de conhecimento destes profissionais sobre a temática do bullying. No que se refere à contribuição do psicólogo neste cenário, Freire e Aires (2012, p. 58) afirmam que "O psicólogo é o profissional apto para realizar um trabalho de prevenção e enfrentamento da violência escolar, ajudando a escola a construir espaços e relações mais saudáveis", e as autoras ainda complementam que para que esta tarefa seja desenvolvida de modo satisfatório, é imprescindível a presença do psicólogo atuando diretamente na escola, e não apenas realizando orientações esporádicas. Em suma, pode-se inferir que é fundamental ofertar formação continuada sobre o bullying a todos os profissionais envolvidos no cenário escolar, de modo a instrumentalizá-los para trabalhar com tal assunto, uma vez que é indiscutível o êxito do trabalho de prevenção realizado por meio de equipe multidisciplinar que, neste caso, envolve diretores, gestores, coordenadores pedagógicos, psicólogos escolares, professores e até mesmo estagiários destas áreas para que desenvolvam práticas na escola.

\section{Ações que reduzam a ocorrência dos casos de bullying}

Quanto à compreensão dos professores acerca do que deve acontecer para que haja uma maior atenção voltada ao bullying visando reduzir a ocorrência dos casos, seis professores afirmaram que a relação entre a família e a escola deve ser reforçada, seis acreditam que projetos de prevenção, conscientização e orientação consistem em estratégias satisfatórias para a redução de casos de bullying, seis acreditam que os valores morais são os responsáveis pela ocorrência ou não dos casos de bullying, três docente pensam que o cumprimento do papel da instituição pode reduzir a ocorrência dos casos e dois professores acreditam que a punição e as leis para que esta ocorra podem reduzir a ocorrência dos casos de bullying. Nogueira (2005, p. 100) enfatiza a necessidade de que haja uma reflexão sobre o bullying, “... é essencial promover a orientação, a conscientização e a discussão a respeito do assunto", tendo em vista que nem toda briga ou discussão deve ser denominada como bullying e que "... a diferença entre um comportamento aceito e um abuso às vezes é muito tênue, e cada caso deve 
ser observado e analisado segundo sua constância e gravidade" (Nogueira, 2005, p. 100).

Considerando os dados de investigação realizada por Salgado, Senra e Lourenço (2014), que efetuou um levantamento de artigos indexados nas bases Web of Science, Psyclnfo, Redalyc, Dialnet e Eric, referentes aos indicadores de efetividade dos programas de intervenção em situações de bullying, dos 165 artigos analisados, evidenciou-se que dos programas implementados para situações de bullying, $30,9 \%$ dos artigos consideram fundamental a capacitação docente; $26,11 \%$ a necessidade de conscientização sobre o fenômeno e $23,6 \%$, o suporte individual e/ou coletivo para os alunos como elementos de maior impacto e eficácia na intervenção em situações de bullying.

Alguns aspectos precisam ser levados em consideração ao se pensar em estratégias de erradicação do fenômeno bullying. O primeiro deles é que é possível intervir de forma direta, quando um episódio ocorre, e de forma indireta, concomitante ao cotidiano escolar (Tognetta \& Vinha, 2008). Para Tognetta (2010, p. 10) "falta-nos, enquanto professores, olhar para o bullying não como brincadeira, mas exatamente como mais uma oportunidade de a partir de um conflito, se aprender a conviver".

\section{Considerações finais}

Considerando o foco deste artigo, que se refere a analisar a compreensão que os professores possuem acerca das razões promotoras do bullying no ambiente escolar; a natureza das razões que podem promover as manifestações deste fenômeno; como estes avaliam as manifestações de bullying na escola e quais as estratégias utilizadas para resolver conflitos do cotidiano escolar, se pode afirmar que os dados coletados com esta investigação se assemelham, em alguma medida, a resultados de outras pesquisas, particularmente no que se refere à necessidade de que os professores conheçam mais sobre o fenômeno bullying, pois é o domínio deste conhecimento que terá repercussões na maneira deles planejarem e realizarem suas intervenções. Entretanto, a continuidade das pesquisas que envolvam esse fenômeno merece especial atenção dos programas de formação inicial e continuada de professores e de outros profissionais de educação, como gestores e coordenadores pedagógicos.

Cabe ressaltar, ainda, além de considerar a necessidade de o professor possuir uma formação adequada para encaminhar problemas como os de bullying no contexto escolar, de que os encaminhamentos desse problema podem ser favorecidos se o professor amparar suas ações por relações de confiança com seus alunos, pois dessa forma estes podem explicitar dificuldades e episódios do cotidiano que Ihes têm perturbado ou conflituado e buscar, em parceria com esse mediador, o encaminhamento do quadro problema em que se veem envolvidos.

É importante ressaltar a necessidade dos cursos de licenciatura organizarem propostas curriculares que subsi- diem a prática dos futuros profissionais, para conhecer e debater cientificamente não somente sobre o bullying, mas sobre todos os tipos de violência que podem ocorrer no ambiente escolar e que, por conseguinte, são relativos às relações interpessoais que ocorrem nesse ambiente, com o propósito de que estratégias e intervenções dos profissionais que atuam na escola tornem-se mais eficazes e consigam prevenir a ocorrência de tais situações.

A formação e capacitação adequada dos profissionais que atuam na escola, bem como a constituição de equipes multidisciplinares, certamente tende a contribuir para auxiliar o cotidiano escolar no encaminhamento de problemas como o bullying. A escola pode se constituir, ademais, como o cenário responsável por elaborar, inclusive, ações de prevenção ao fenômeno em conjunto com os pais dos alunos, principalmente tendo em vista que dentre as escolas participantes da pesquisa, a maioria dos professores pesquisados afirmou não haver projetos de intervenção/prevenção ao bullying. Entretanto, cabe ressaltar que as ações perante o problema do bullying não possuem receitas prontas (Silva \& Rosa, 2013) e não são cartilhas entregues aos professores (Avilés Martínez, 2013) que resolverão a situação problemática, mas se deve avaliar o contexto social, com suas particularidades, as quais envolvem tanto a família quanto a escola. Considera-se importante o protagonismo da escola e de seus profissionais na construção de alternativas para os problemas evidenciados nesse contexto.

É necessário que o desafio do encaminhamento do problema seja assumido por esses profissionais. E, para que isso ocorra, ressalta-se a ênfase atribuída por Tognetta (2013, p. 11) ao encaminhamento de problemas como o bullying que demanda "uma análise séria e global das relações interpessoais que imperam na comunidade educativa, dos valores que se promovem nela e como seus membros participam nos projetos de convivência na escola". Nesse sentido, para todos os profissionais que atuam na escola, sentirem-se pertencentes e responsáveis por esse contexto é algo indispensável se o que se deseja é um projeto de escola que colabore com a construção e o alargamento das capacidades dos alunos, a promoção de experiências de convivência saudáveis em dimensões: cognitivas, afetivas, morais, entre outras, inibindo situações de conflitos entre pares como é o caso do bullying.

Salienta-se a importância da realização de pesquisas que busquem conhecer outros aspectos inerentes ao bullying no ambiente escolar, bem como planejamento de projetos de intervenção e, principalmente, de prevenção, que possam ser adotados pelas escolas a fim de minimizar a ocorrência do problema.

\section{Referências}

Almeida, A., Lisboa, C. \& Caurcel, M. J. (2007). Por qué ocurren los malos tratos entre iguales? Explicaciones causales de adolescentes portugueses y brasileños. Revista Interamericana de Psicologia, 41 (2), 107-118. 
Associação Brasileira Multiprofissional de Proteção à Infância e à Adolescência [Abrapia]. (2008). O que é Bullying. Construir Notícias, 7 (40).

Avilés Martínez, J. M. (2006). Bullying: el maltrato entre iguales. Agresores, víctimas y testigos en la escuela. Salamanca: Amarú.

Avilés Martínez, J. M. (2013). Bullying: guia para educadores. Campinas: Mercado de Letras.

Borsa, J. C.; Petrucci, G. W., \& Koller, S.H. (2015). A participação dos pais nas pesquisas sobre o bullying escolar. Psicologia Escolar e Educacional, 19(1), 41-48.

Esteve, C. E. A. \& Arruda, A. L. M. M. (2014). Bullying: Quando a brincadeira fica séria, causas e consequências. Saberes da Educação, 5 (1).

Fante, C. (2005). Fenômeno bullying: como prevenir a violência nas escolas e educar para a paz (2a. ed.). Campinas: Verus Editora.

Fante, C. \& Pedra, J. A. (2008). Bullying escolar: perguntas e respostas. Porto Alegre: Artmed.

Freire, A. N. \& Aires, J. S. (2012). A contribuição da psicologia escolar na prevenção e no enfrentamento do Bullying. Psicologia Escolar e Educacional, 16(1), 55-60.

Gisi, M. L., Vaz, F. A. B., \& Valter, C. C. N. (2012). Bullying: um desafio para a formação de professores. Em Anais Seminário de Pesquisa da Região Sul, Caxias do Sul: UCS.

Lopes Neto, A. A. (2005). Bullying - Comportamento agressivo entre estudantes. Jornal de Pediatria, 81 (5), 164-172.

Lopes Neto, A. A. \& Saavedra, L. H. (2003). Diga não para o bullying: Programa de redução do comportamento agressivo entre estudantes. Rio de Janeiro: Abrapia.

Marriel, L. C., Assis, S. G., Avanci, J. Q., \& Oliveira, R. V. C. (2006). Violência escolar e auto-estima de adolescentes. Cadernos de Pesquisa, 36 (127), 35-50.

Moura, D. R., Cruz, A. C. N., \& Quevedo, L. Á. (2011). Prevalência e características de escolares vítimas de bullying. Jornal de Pediatria, 87 (1), 19-23.

Nogueira, R. M. C. D. P. A. (2005). A prática de violência entre pares: o bullying nas escolas. Revista Iberoamericana de Educación, 37, 93-102.

Pereira, B. O. (2002). Para uma escola sem violência: Estudo e prevenção das práticas agressivas entre crianças. Porto, Portugal: Imprensa Portuguesa.

Pereira, B. O., Silva, M. I., \& Nunes, B. (2009). Descrever o bullying na escola: estudo de um agrupamento de escolas no interior de
Portugal. Revista Diálogo Educacional, 9 (28), 455-466.

Rosa, M. J. A. (2010). Violência no Ambiente Escolar: refletindo sobre as consequências para o processo ensino aprendizagem. Fórum Identidades, 4 (8), 143-158.

Salgado, F. S., Senra, L. X., \& Lourenço, L. M. (2014). Effectiveness indicators of bullying intervention programs: A systematic review of the international literature. Estudos de Psicologia, 31 (2), p. 179190, abril/junho.

Silva, E. N. \& Rosa, E. C. S. (2013). Professores sabem o que é bullying? Um tema para a formação docente. Psicologia Escolar e Educacional, 17 (2), 329-338.

Silva, A. B. B. (2010). Bullying: mentes perigosas nas escolas. Rio de Janeiro: Objetiva.

Silva, J. L., Oliveira, W. A., Silva. M. A. I, Pereira, B.O., \& Cecilio, S. (2015) Estudo exploratório sobre as concepções e estratégias de intervenção de professores em face do bullying escolar. Revista Psicologia: Teoria e Prática, 17(3), 189-199.

Tognetta, L. R. P. (2010). Bullying: de onde vem a Violência que assola a Escola? Em A. Garcia (Org.), Pesquisas sobre o Relacionamento Interpessoal. Vitória: Editora da ABPRI.

Tognetta, L. R. P. (2013). Prefácio à edição brasileira. Em J. M. Avilés Martínez (Org.), Bullying: guia para educadores. Campinas: Mercado de Letras.

Tognetta, L. R. P. \& Vinha, T.P. (2010). Bullying e intervenção no Brasil: um problema ainda sem solução. Em Congresso Nacional De Psicologia Da Saúde: Saúde, Sexualidade e gênero (Org.), Anais eletrônicos. Lisboa: ISPA - Instituto Universitário.

Tognetta, L. R. P. \& Bozza, T. C. L. (2010). Cyberbullying: quando a violência é virtual - Um estudo sobre a incidência e sua relação com as representações de si em adolescentes. Em A. M. Guimarães \& Pacheco e Zan, D. D. Anais do I Seminário Violar: Problematizando juventudes na contemporaneidade. Campinas: FE/UNICAMP.

Tognetta, L. R. P., Leme, M. I. S., \& Vicentin, V. F. (2013). Quando os conflitos nos pertencem: uma reflexão sobre as regras e a intervenção aos conflitos na escola que pretende formar para a autonomia (Vol. 3). Campinas: S.P.: Mercado de Letras.

Tognetta, L. R. P. \& Vinha, T. P. (2008). Estamos em conflito: eu, comigo e com você! Uma reflexão sobre o bullying e suas causas afetivas. Em J. L. Cunha \& L. S. C. Dani (Orgs.), Escola, conflitos e violências. Santa Maria: Ed. da UFSM.

Trevisol, M. T. C. \& Uberti, L. (2013). Bullying na escola: inquirindo sobre as razões promotoras dos conflitos "entre" e "dos" alunos. Relatório de Pesquisa. Joaçaba, SC, Universidade do Oeste de Santa Catarina. 
Trevisol, M.T.C. \& Uberti, L. (2015). Bullying na escola: a compreensão do aluno no papel de testemunha. Revista Psicologia: Teoria e Prática, 17(3), 164-176.

Recebido em: 25/02/2015

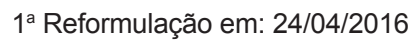

2a Reformulação em: 26/06/2016

Aprovado em: 29/06/2016

\section{Sobre os autores}

Maria Teresa Ceron Trevisol (mariateresa.trevisol@unoesc.edu.br)

Doutora em Psicologia Escolar e do Desenvolvimento Humano pela Universidade de São Paulo. Docente da graduação e do Programa de PósGraduação em Educação (PPGEd) - Mestrado da Universidade do Oeste de Santa Catarina.

Carlos Alexandre Campos (carloscampos_psico@yahoo.com.br)

Graduando em Psicologia pela Universidade do Oeste de Santa Catarina. Bolsista de Iniciação Científica do CNPq.

Pesquisa realizada com apoio financeiro do Conselho Nacional de Desenvolvimento Científico e Tecnológico - CNPq. 
